\title{
Temporary Epicardial Pacing After Valve Replacement: Incidence And Predictors
}

\author{
Montaser Elsawy Abd Elaziz, $\mathbf{M D}^{1,2}$, Amr Mohammad Allama, MD ${ }^{1}$ \\ ${ }^{1}$ Cardiothoracic Surgery Department, Menoufia University, Almenoufia, Egypt; ${ }^{2}$ Faculty Of Medicine, Jazan University, Jazan, Saudi Arabia.
}

\section{INTRODUCTION}

Temporary pacemaker wires are usually inserted in patients after valve replacement and may be beneficial for optimizing myocardial function in patients that develop postoperative hemodynamically significant arrhythmias [Elmi 2002]. Indications for temporary cardiac pacing (TCP) are atrial, ventricular or atrioventricular pacing for bradyarrhythmias and for management of both atrial and ventricular tachyarrhythmias [De Belder 1990; Liebold 1998].

Pacemaker wires have two ends - one end has a small needle, which is passed into the myocardial surface, then is cut off. The needles may be coiled or clipped for better fixation. On the other end, the larger needle is used to penetrate the body wall, to pass the wire through to the body surface. There is debate about the ideal site for wire insertion, with agreement that the most common site of insertion is in the right ventricle [Hurle 2002].

The complications of PMWs include: bleeding, tamponade, arrhythmias, and even retention with its serious hazards [Kapoor 2011; Smith 2013]. During removal of PMWs, there may be atrial or ventricular lacerations which lead to bleeding and to developing tamponade. This may prolong the hospital stay of patients, especially patients on anticoagulant medications. This study was done on patients who received pacing wires during cardiac surgery. The purpose of the study was to predict risk factors that could lead to cardiac pacing after valve surgery.

\section{PATIENTS AND METHODS}

\section{Study Design}

Between November 2012 and February 2017, a retrospective observational study was done on 90 patients who underwent isolated valve replacement in the Cardiothoracic Surgery Department, Menoufia University Hospital, Egypt. After Menoufia Ethics Committee approval for the study protocol, we reviewed database records of patients from the cardiothoracic surgery department and the cardiac intensive care unit in our hospital. Patients excluded from the study were

Received Fune 11, 2017; received in revised form August 1, 2017; accepted August $12,2017$.

Montaser Elsawy Abd Elaziz, MD, Assistant Professor of Cardiothoracic Surgery, Faculty of Medicine, Menoufia University, Yassin Abdel Ghaffar street, Shibin Elkoum, Almenoufia, Egypt \& Assistant Professor of Cardiothoracic Surgery, Faculty of Medicine, Jazan University, Jazan, Saudi Arabia;(e-mail:mnt_swy@ yahoo.com) those who underwent redo valve surgery, combined valve and coronary artery bypass surgery, and patients with preoperative high degree atrioventricular block (AVB).

Patients were classified into two groups: group A $(n=30)$ for whom we didn't insert pacemaker wires (PMWs) and did not need to be paced, and group B $(n=60)$ who had PMWs fixed. Group B was further subdivided into patients who needed temporary cardiac pacing (TCP) and those who did not need TCP. All patient's characteristics were studied to detect the predictors of postoperative pacing. These included all demographic data, preoperative medical history, including history of drug use, and detailed operative data.

The primary outcome was the detection of the indication of TCP (if patients were paced at the time of chest closure or at any time before hospital discharge).

Preoperative arrhythmias were defined as atrial fibrillation (AF), low grade AVB, or a bundle branch block that were diagnosed by electrocardiogram (ECG). The types of valve surgery were: mitral valve, aortic valve, and multiple valve (double or triple). The study did not include isolated tricuspid valve surgery, as all surgical procedures on tricuspid valves were included in the category of multiple valve surgery.

\section{Operative Procedures}

Median sternotomy was the standard incision in all cases. If the surgery was on the mitral valve, the cardiopulmonary bypass circuit was connected through cannulation of the ascending aorta with cannulation of both superior and inferior vena cava. A left atriotomy approach was preferred by us to reach the mitral valve. In aortic valve surgery only aortic and double-stage venous cannulae were used, with left atrial-ventricular venting by a cannula into right superior pulmonary vein. Systemic perfusion pressure was maintained at $60-80 \mathrm{mmHg}$, with a rate of $2-2.5 \mathrm{~L} / \mathrm{min} / \mathrm{m} 2$. Antegrade cold blood cardioplegia at a rate of $200-250 \mathrm{ml} / \mathrm{min}$ was used for myocardial protection, with patients' temperature usually kept at 28-32C. Cold saline was used to cool the myocardial surface. Blunt debridement of the calcified valve annulus was done carefully.

We assessed which patient was in need for PMWs insertion according to the condition of each patient separately. If there was a heavily calcified annulus in multiple valve surgery and prolonged aortic cross clamp time in a patient with difficult weaning from cardiopulmonary bypass (CPB), we usually inserted ventricular PMWs. If AV block occurred after separation from $\mathrm{CPB}$, we add atrial $\mathrm{PMWs}$. After perfect hemostasis and careful securing of sites of purse string sutures, we closed the sternotomy with placement of mediastinal drains. Then the patients were transferred ventilated to the intensive care unit (ICU), with close monitoring of ECG. 
Table 1. Preoperative Patient Characteristics

\begin{tabular}{|c|c|c|c|c|}
\hline Variables n (\%) & Total $n=90$ & $\begin{array}{c}\text { Group A } \\
(n=30)\end{array}$ & $\begin{array}{c}\text { Group B } \\
(n=60)\end{array}$ & $P$ \\
\hline \multicolumn{5}{|l|}{ Age $(65.8 \pm 11.07)$} \\
\hline$<65$ years & $60(66.7)$ & $25(41.7)$ & $35(58.3)$ & $.02 *$ \\
\hline$>65$ years & $30(33.3)$ & $5(16.7)$ & $25(83.3)$ & \\
\hline \multicolumn{5}{|l|}{ Sex } \\
\hline Male & $70(77.7)$ & $20(28.6)$ & $50(71.4)$ & .07 \\
\hline Female & $20(22.3)$ & $10(50)$ & $10(50)$ & \\
\hline Diabetes mellitus & $30(33.3)$ & $10(33.3)$ & $20(66.7)$ & 1 \\
\hline \multicolumn{5}{|l|}{ NYHA class } \\
\hline$|-| \mid$ & $60(66.7)$ & $20(33.3)$ & $40(66.7)$ & 1 \\
\hline III-IV & $30(33.3)$ & $10(33.3)$ & $20(66.7)$ & \\
\hline History of arrhythmias & $9(10)$ & $2(22.3)$ & $7(77.7)$ & .4 \\
\hline \multicolumn{5}{|l|}{ Preop drugs } \\
\hline Beta Blockers & $22(24.5)$ & $7(31.8)$ & $15(68.2)$ & .86 \\
\hline Digoxin & $15(16.7)$ & $3(20)$ & $12(80)$ & .23 \\
\hline Amiodarone & $6(6.6)$ & $1(16.6)$ & $5(83.4)$ & .36 \\
\hline \multicolumn{5}{|l|}{ Pulmonary Artery } \\
\hline \multicolumn{5}{|l|}{ Pressure $(40 \pm 14.07)$} \\
\hline$<45 \mathrm{mmHg}$ & $75(83.3)$ & $25(33.3)$ & $50(66.7)$ & 1 \\
\hline$>45 \mathrm{mmHg}$ & $15(16.7)$ & $5(33.3)$ & $10(66.7)$ & \\
\hline \multicolumn{5}{|l|}{ Preop EF (58 \pm 15.3$)$} \\
\hline$>40 \%$ & $70(77.7)$ & $25(37.7)$ & $45(64.3)$ & .37 \\
\hline$<40 \%$ & $20(22.3)$ & $5(25)$ & $15(75)$ & \\
\hline \multicolumn{5}{|c|}{ Lt atrial diameter $(4.6 \pm 0.9)$} \\
\hline$<5 \mathrm{~cm}$ & $60(66.7)$ & $20(33.3)$ & $40(66.7)$ & 1 \\
\hline$>5 \mathrm{~cm}$ & $30(33.3)$ & $10(33.3)$ & $20(66.7)$ & \\
\hline
\end{tabular}

\section{Statistical Analysis}

Statistical analysis was done by Statistical Package for Social Sciences (SPSS, version 19). The relationships between TCP and possible predictors were analyzed by Chi square test. Multiple logistic regression was used to identify the predictive factors of postoperative TCP in the multivariate analysis. Only parameters that were of statistical significance entered in the multivariate analysis. A statistically significant $P$-value if it was $\leq .05$.

\section{RESULTS}

In Table 1, we noticed no statistically significant difference between both groups regarding all of demographic data except that of age $(P=.02)$. PMWs were left in place for at least 80 hours, and the mean duration of pacing was $60 \pm 28$ hours. Among patients in group B, only 20\% (12/60) needed TCP. Conduction abnormalities were diagnosed mainly by 12-lead ECGs, and these were mainly due to postoperative atrioventricular block in $66.7 \%(8 / 12)$ of patients, sinus bradycardia in $8.3 \%(1 / 12)$, Asystole in $8.3 \%(1 / 12)$, and low cardiac output in $16.6 \%(2 / 12)$.

Table 2 shows no statistically significant difference between both groups regarding the operative data, such as type of valve surgery, cardiopulmonary bypass and aortic cross-clamp
Table 2. Operative Data

\begin{tabular}{lcccc}
\hline Variables n (\%) & Total $n=90$ & $\begin{array}{c}\text { Group A } \\
(\mathrm{n}=30)\end{array}$ & $\begin{array}{c}\text { Group B } \\
(\mathrm{n}=60)\end{array}$ & $P$ \\
\hline Surgery & & & & \\
Mitral valve & $30(33.3)$ & $10(33.3)$ & $20(66.7)$ & .6 \\
Aortic valve & $20(22.3)$ & $5(25)$ & $15(75)$ & \\
Multiple valve & $40(44.4)$ & $15(37.5)$ & $25(62.5)$ & \\
Annular calcification & $35(38.9)$ & $5(14.3)$ & $30(85.7)$ & $.002 *$ \\
CPB time & $(99.6 \pm 3.4)$ & & & \\
$<100$ min & $70(77.7)$ & $20(28.6)$ & $50(71.4)$ & .07 \\
$>100$ min & $20(22.3)$ & $10(50)$ & $10(50)$ & \\
Ao cross clamp time & $(58.8 \pm 8.7)$ & & & \\
$<65$ min & $65(72.2)$ & $25(38.5)$ & $40(61.5)$ & .09 \\
$>65$ min & $25(27.8)$ & $5(20)$ & $20(80)$ & \\
\hline
\end{tabular}

Test of significance is chi-square, CPB: Cardiopulmonary Bypass

times. But there was a significant difference between both groups regarding the annular calcification $(P=.002)$.

Table 3 shows the univariate analysis of patients' characteristics in group B, regarding the need for pacing.

Table 4 shows preoperative drugs use, where patients on digoxin preoperatively were more likely to need pacing than those on beta-blockers, or amiodarone.

Table 5 shows that $10 \%$ of patients who had mitral valve surgery, $6.6 \%$ who underwent aortic valve replacement and $36 \%$ who had combined valve surgery required pacing.

Table 6 shows patient characteristics of those who required pacing. Old age, DM, PAP $>45 \mathrm{mmHg}$, advanced NYHA class, preoperative use of digoxin, multiple valve surgery, annular calcification, and aortic cross-clamp time $>65 \mathrm{~min}-$ utes were all significantly more likely to need pacing.

\section{DISCUSSION}

Postoperative temporary pacing differs from one cardiac center to another in valve surgery. Many centers use only ventricular wires, and others use both atrial and ventricular wires. Temporary pacing wires can cause complications. Little research was done to determine the predictors of postoperative pacing in valve surgery patients.

Infection, myocardial injury, perforation, hemopericardium were the most common complications of PMWs [Bojar 2004; Timothy 2004]. Research has shown that most patients do not require cardiac pacing. Because of the reported complications, many cardiac surgery centers used PMWs within very narrow limits, and restricted their use only for patients complicated by bradycardia with low cardiac output, AV block, and nodal or junctional arrhythmias [Puskas 2003]. Only $2.6 \%$ of patients who were not diabetic, had no preoperative arrhythmias, or did not need pacing to come off $\mathrm{CPB}$, required pacing during the postoperative period [Bethea 2005]. Many centers found this percentage was high for these group of patients and inserted at least one ventricular PMW.

Ferrari and Gupta studied the rate and the determinant factors that predict the need for TCP after valvular surgery [Ferrari 2011; Gupta 2012]. We restricted or did not insert 
Table 3. Univariate Analysis for the Relationship Between Basic Patient's Characteristics and Postoperative Temporary Pacing in Group B

\begin{tabular}{|c|c|c|c|c|}
\hline Variables n (\%) & $\begin{array}{l}\text { Total } \\
\mathrm{n}=60\end{array}$ & $\begin{array}{l}\text { W/O pacing } \\
\quad(n=48)\end{array}$ & $\begin{array}{l}\text { With pacing } \\
\qquad(n=12)\end{array}$ & $P$ \\
\hline \multicolumn{5}{|l|}{ Age (58.3 \pm 9.9$)$} \\
\hline$<65$ years & $35(58.3)$ & $33(94.3)$ & $2(5.7)$ & $.001 *$ \\
\hline$>65$ years & $25(41.7)$ & $15(60)$ & $10(40)$ & \\
\hline \multicolumn{5}{|l|}{ Sex } \\
\hline Male & $50(83.3)$ & $42(84)$ & $8(16)$ & .08 \\
\hline Female & & $10(11.1)$ & $6(60)$ & $4(40)$ \\
\hline \multicolumn{5}{|l|}{ DM } \\
\hline No & $40(66.6)$ & $39(97.5)$ & $1(2.5)$ & $.001 *$ \\
\hline Yes & $20(33.4)$ & $9(45)$ & $11(55)$ & \\
\hline \multicolumn{5}{|l|}{ NYHA class } \\
\hline I-II & $40(66.6)$ & $36(90)$ & $4(10)$ & $.006 *$ \\
\hline III-IV & $20(33.4)$ & $12(60)$ & $8(40)$ & \\
\hline \multicolumn{5}{|c|}{ Preop arrhythmia } \\
\hline No & $53(88.3)$ & 43(81.1) & $10(18.9)$ & .5 \\
\hline Yes & $7(11.7)$ & & $5(71.4)$ & $2(28.6)$ \\
\hline \multicolumn{5}{|l|}{ PAPs $(41 \pm 18.7)$} \\
\hline$<45 \mathrm{mmHg}$ & $50(83.3)$ & $47(94)$ & $3(6)$ & $.00 *$ \\
\hline$>45 \mathrm{mmHg}$ & $10(11.1)$ & $1(10)$ & $9(90)$ & \\
\hline \multicolumn{5}{|c|}{ Preop EF(53.5 \pm 15$)$} \\
\hline$>40 \%$ & $45(75)$ & $40(88.9)$ & $5(11.1)$ & .002 \\
\hline$<40 \%$ & $15(25)$ & $8(53.3)$ & $7(46.7)$ & \\
\hline \multicolumn{5}{|c|}{ Lt atrial size $(4 \pm 1)$} \\
\hline$<5 \mathrm{~cm}$ & $40(66.6)$ & $33(82.5)$ & $17(17.5)$ & .5 \\
\hline$>5 \mathrm{~cm}$ & $20(33.4)$ & $15(75)$ & $5(25)$ & \\
\hline
\end{tabular}

PMWs in valve replacement in these patients: (1) young age with no preoperative history of risk factors, (2) isolated single valve replacement with minimal calcification, (3) easily coming off of cardiopulmonary bypass and vitally stable on the least inotropic doses. These restrictions for PMWs placement were also according to the surgeon's discretion, whose main aim was to safely select patients and avoid unneeded complications. The decision was also weighed according to the available data in the previous studies.

The indications for cardiac pacing was attributed to two factors: (1) mechanical damage to the $\mathrm{AV}$ node or the His bundle caused by an intraoperative technique, or (2) ischemic injury to the conduction system during periods of cardioplegia. These two reasons may exaggerate previous rhythm abnormalities or induce de novo ones. We had only 20\% (12/60) of patients with PMWs that required pacing.. This percentage was slightly lower than that reported in a study done by Alwaqfi et al. [AlWaqfi 2014] who reported a percentage of $24.9 \%$ of patients who needed pacing in the postoperative period. This may be attributed to the fact that we operated on patients with only isolated valve disease, and combined valve and coronary artery bypass surgery patients were excluded from our study, in contrast to the study done by Alwaqfi et al., where they included combined valve surgery and coronary patients.
Table 4. Univariate Analysis for Use of Temporary Pacing in Group B According to Preoperative Medications

\begin{tabular}{lcccc}
\hline & Total $\mathrm{n}=60$ & $\begin{array}{c}\text { W/O pacing } \\
\mathrm{n}=48\end{array}$ & $\begin{array}{c}\text { With pacing } \\
\mathrm{n}=12\end{array}$ & $P$ \\
\hline $\begin{array}{c}\text { Beta Blockers } \\
\text { No }\end{array}$ & $45(75)$ & $37(82.2)$ & $8(17.8)$ & .45 \\
Yes & $15(25)$ & $11(73.3)$ & $4(26.7)$ & \\
$\begin{array}{l}\text { Digoxin } \\
\text { No }\end{array}$ & $48(88)$ & $46(95.8)$ & $2(4.2)$ & $.00 *$ \\
Yes & $12(20)$ & $2(16.7)$ & $10(83.3)$ & \\
Amiodarone & & & & \\
No & $55(91.7)$ & $45(81.8)$ & $10(18.2)$ & .25 \\
Yes & $5(8.3)$ & $3(60)$ & $2(40)$ &
\end{tabular}

Regarding the relationship between age of patients and cardiac pacing, we used univariate and multivariate analysis and found that the group of patients who were predicted more to need postoperative pacing were those with older age $>65$ years old (odds ratio $=11$ ). Old age was considered as a risk factor for developing postoperative arrhythmias. This is because of the decreased threshold for postoperative arrhythmias induced by anatomical and physiological changes in the myocardial tissue in these group of patients [Mathew 2004]. In a review of 915 consecutive adults with sinus rhythm who underwent valve surgery, the odds ratio for developing postoperative atrial fibrillation was 1.51 per decade [Asher 1998].

In a few studies, gender was considered as a predictor of postoperative pacing. Gender had no predictive value for pacing in studies done by Elahi et al. and Ferrari et al. [Elahi 2006; Ferrari 2011]. This was similar to our study where gender was not a determinant factor of need for cardiac pacing.

There has been controversy about the role of preoperative arrhythmia as a predictive factor for postoperative pacing [Berdajs 2008; Ferrari 2011]. In our study, preoperative arrhythmia was not a determinant factor for postoperative pacing in the multivariate analysis.

Pacing was needed in patients with advanced NYHA class (III-IV) to improve cardiac functions after coming off CPB. This is because these group of patients had impaired left ventricular functions and were at high risk of developing conduction abnormalities [Linde 2010]. Advanced NYHA class was a significant predictor of TCP in both univariate and multivariate analysis in our study. This finding was consistent with that in the study of Gordon et al. [Gordon 1998]. By contrast, advanced NYHA status was not a predictor of TCP in a study by Ferrari et al. [Ferrari 2012].

Diabetes mellitus was found to be a highly significant predictor of postoperative pacing (odds ratio, 47.6) in our study.

Pulmonary hypertension (PAP) was shown to be a significant predictor for postoperative pacing after valve surgery in many studies. It was reported as a risk factor for postoperative AVB following aortic valve surgery by Limongelli et al. [Limongelli 2003]. It is believed to have significant effect on the right ventricular geometry (dimensions and shape), and interventricular septal thickness, causing progressive mechanical stretch that could affect the conduction system by changing the electrophysiological properties of its fibers. In our study, increased PAP was a significant predictor of TCP 
Table 5. Univariate Analysis for Operative Data Related to Postoperative Temporary Pacing in Group B

\begin{tabular}{|c|c|c|c|c|}
\hline Variables n (\%) & Total $n=60$ & $\begin{array}{c}\text { W/O pacing } \\
(\mathrm{n}=48)\end{array}$ & $\begin{array}{l}\text { With pacing } \\
\qquad(\mathrm{n}=12)\end{array}$ & $P$ \\
\hline \multicolumn{5}{|l|}{ Surgery } \\
\hline Mitral valve & $20(33.3)$ & $18(90)$ & $2(10)$ & .017 \\
\hline Aortic valve & $15(25)$ & $14(93.4)$ & $1(6.6)$ & .1 \\
\hline Multiple valve & $25(41.7)$ & $16(64)$ & $9(36)$ & $.009 *$ \\
\hline \multicolumn{5}{|l|}{ Calcified annulus } \\
\hline No & $30(50)$ & $28(93.4)$ & $2(6.6)$ & $.009 *$ \\
\hline Yes & $30(50)$ & $20(66.6)$ & $10(33.4)$ & \\
\hline \multicolumn{5}{|c|}{ 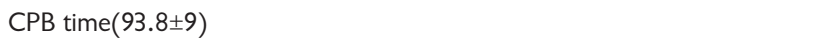 } \\
\hline$<100$ min & $50(83.3)$ & $42(84)$ & $8(16)$ & .08 \\
\hline$>100 \mathrm{~min}$ & $10(16.7)$ & $6(60)$ & $4(40)$ & \\
\hline \multicolumn{5}{|l|}{$\begin{array}{l}\text { Ao cross clamp } \\
(56.5 \pm 10.6)\end{array}$} \\
\hline$<65$ min & $40(66.6)$ & $38(95)$ & $2(5)$ & $.00 *$ \\
\hline$>65 \mathrm{~min}$ & $20(33.4)$ & $10(50)$ & $10(50)$ & \\
\hline
\end{tabular}

by both univariate and multivariate analysis (odds ratio, 141).

Some authors reported that preoperative use of digoxin and beta-blockers as predictors of postoperative conduction abnormalities [Jokinen 2004; Berdajs 2008]. In a study done by Berdjas et al. [Berdajs 2008] on patients who had mitral valve surgery, both digoxin and beta blockers were shown to significantly lower the risk of conduction abnormalities. In our study, only digoxin was a predictor of postoperative pacing. The mechanism of action of digoxin is that it improves myocardial contractility in heart failure by increasing the intracellular calcium concentration. However, it increases the vagal inhibitory effect (vagomimetic effect) on the sinoatrial and atrioventricular conduction and prolongs the atrioventricular node refractory period, and so increases the need for postoperative TCP [Jokinen 2004]. Also, digoxin has, even at therapeutic levels, an arrhythmogenic effect on ischemic myocardium [Krum 1995], which may include periods of prolonged aortic cross-clamping time.

In our study, the type of operation was a determinant of TCP in the univariate analysis and multivariate analysis. Patients who had multiple valve surgery and underwent extensive debridement of the heavily calcified annulus at the atrioventricular sinus area (the posterior commissure of the anterior mitral leaflet, the commissure between right and non-coronary cusps of the aortic valve, and the septal leaflet of the tricuspid valve) were at high risk of mechanical injury to the atrioventricular node and conduction system and were significantly more likely to need TCP after coming off CPB. In these patients, it may be difficult to deliver adequate cardioplegic solution for myocardial protection, leading to further exacerbation of preexisting conduction abnormalities. These results were similar to that in studies by Gordon et al. and Erdogan et al. [Gordon 1998; Erdogan 2006] who focused their studies on the predictors of permanent pacing in aortic valve surgery.

Patients with prolonged periods of aortic cross clamp time (more than 65 minutes) were more likely to need postoperative pacing in our study. This was similar to that in the study
Table 6. Multivariate Analysis of Factors Related to Temporary Cardiac Pacing in Group B

\begin{tabular}{lccc}
\hline Variables & $\begin{array}{c}\text { Odds } \\
\text { Ratio }\end{array}$ & $\begin{array}{c}95 \% \text { confidence } \\
\text { interval }(\mathrm{Cl})\end{array}$ & $P$ \\
\hline Age $>65$ & 11 & $2.1: 56.5$ & $.004^{*}$ \\
Diabetes Mellitus & 47.6 & $25.4: 418$ & $.005^{*}$ \\
NYHA class III-IV & 6 & $1.5: 23.5$ & $<.001 *$ \\
Preop digoxin & 115 & $14.5: 916.7$ & $<.001 *$ \\
PAP>45 mmHg & 141 & $131: 1512$ & $<.001 *$ \\
Multiple valve surgery & 6 & $1.4: 25.2$ & $.01 *$ \\
Calcified annulus & 7 & $1.4: 35.5$ & $.01 *$ \\
CPB $>100$ min & 3.5 & $0.8: 15.2$ & .09 \\
Aortic cross clamp $>$ & 19 & $3.5: 101$ & $.006 *$ \\
65 min & & &
\end{tabular}

done by Schurr et al. [Schurr 2010] on the incidence of pacemaker implantation after aortic valve replacement. This may be attributed to two causes. First, myocardial edema that may happen after prolonged cross clamp time, and second is ischemic injury to the sinoatrial node, the atrioventricular node, and bundle of His.

\section{CONCLUSION}

This study determined the predictors of postoperative pacing after valve replacement, which included: old age > 65 years, NYHA class (III-IV), DM, PAPs $\geq 45 \mathrm{mmHg}$, preoperative digoxin use, multiple valve surgery, aortic crossclamp time $\geq 65 \mathrm{~min}$, and heavy annular calcification. It also showed little need for pacing in many cases, especially with proper selection of patient characteristics that lower the use of pacing wires.

\section{REFERENCES}

AlWaqfi NR, Ibrahim KS, Khader YS, Abu Baker A. 2014. Predictors of temporary epicardial pacing wires use after valve surgery. J cardiothoracic surgery 9:33.

Asher CR1, Miller DP, Grimm RA, Cosgrove DM 3rd, Chung MK. 1998. Analysis of risk factors for development of atrial fibrillation early after cardiac valvular surgery. Am J Cardiol 82:892-895.

Berdajs D, Schurr UP, Wagner A, et al. 2008. Incidence and pathophysiology of atrioventricular block following mitral valve replacement and ring annuloplasty. Eur J Cardiothorac Surg 34:55-61.

Bethea BT, Salazar JD, Grega MA. 2005. Determining the utility of temporary pacing wires after coronary artery bypass surgery. Annals of Thoracic Surgery 79:104-107.

Bojar RM. Manual of Perioperative Care in Adult Cardiac Surgery, 4th edn. Malden, MA: Blackwell Publishing, 2004.

De Belder MA, Malik M, Ward DE, Camm J. 1990. Pacing modalities for tachycardia termination. Pacing Clin Electrophysiol 13:231-247.

Elahi MM, Darren L, Dhannapuneni RRV. 2006. Predictors of permanent pacemaker implantation during the early postoperative period after valve surgery. Tex Heart Inst J 33:455-457.

Elmi F, Khalighi K, Tullo NG. 2002. Natural history and predictors of temporary epicardial pacemaker wire function in patients after open heart surgery. Cardiology 98:175:180. 
Erdogan HB, Kayalar N, Ardal H, et al. 2006. Risk factors for requirement of permanent pacemaker implantation after aortic valve replacement. J Card Surg 21:211-215.

Ferrari AD, Süssenbach CP, Guaragna JC, et al. 2011. Atrioventricular block in the postoperative period of heart valve surgery: incidence, risk factors and hospital evolution. Rev Bras Cir Cardiovasc 26:364-372.

Gordon RS, Cohen G, Joan I, Gideon C, Ralph-Edwards AL. 1998. Permanent cardiac pacing after a cardiac operation: Predicting the use of permanent pacemakers. Ann Thorac Surg 66:1698-1704.

Gupta P, Jines P, Gossett JM, et al. 2012. Predictors for use of temporary epicardial pacing wires after pediatric cardiac surgery. J Thorac Cardiovasc Surg 144:557-562.

Hurle A, Gomez-Plana J, Sanchez J, et al. 2002. Optimal location for temporary epicardial pacing leads following open heart surgery. Pacing and Clinical Electrophysiology 25:1049-1052.

Jokinen JJ, Mustonen PK, Hippelainen MJ, Rehnberg LS, Hartikainen JE. 2004. Effects of coronary artery bypass related conduction defects: a 10-year follow-up study. Scand Cardiovasc J 38:235-239.

Kapoor A, Syal S, Gupta N, Gupta A. 2011. Right paracardiac mass due to organized pericardial hematoma around retained epicardial pacing wires following aortic valve replacement. Interact CardioVasc Thorac Surg 13:104-106.

Krum H, Bigger JT Jr, Goldsmith RL, Packer M. 1995. Effect of longterm digoxin therapy on autonomic function in patients with chronic heart failure. J Am Coll Cardiol 25:289-294.
Liebold A, Wahba A, Bimbaum DE. 1998. Low-energy cardioversion with epicardial wire electrodes: new treatment of atrial fibrillation after open heart surgery. Circulation 98:883-886.

Limongelli G, Ducceschi V, D'Andrea A, et al. 2003. Risk factors for pacemaker implantation following aortic valve replacement: a single center experience. Heart 89:901-904.

Linde C, Daubert C. 2010. Cardiac resynchronization therapy in patients with New York Heart Association class I and II heart failure: an approach to 2010. Circulation 122:1037-1043.

Mathew JP, Fontes ML, Tudor IC, et al. 2004. A multicenter risk index for atrial fibrillation after cardiac surgery. JAMA 291:1720-1729.

Puskas JD, Sharoni E, Williams WH, et al. 2003. Is routine use of temporary epicardial pacing wires necessary after either OPCAB or conventional CABG/CPB? Heart Surgery Forum 6: E103-E106.

Schurr UP, Berli J, Berdajs D, et al. 2010. Incidence and risk factors for pacemaker implantation following aortic valve replacement. Interact Cardiovasc Thorac Surg 11:556-560.

Smith DE 3rd, DeAnda A Jr, Towe CW, Balsam LB. 2013. Retroaortic abscess: an unusual complication of a retained epicardial pacing wire. Interact Cardiovasc Thorac Surg 16:221-223.

Timothy PR, Rodeman BJ. 2004. Temporary pacemakers in critically ill patients: assessment and management strategies. 270 American Association of Critical-Care Nurses Clinical Issues 15: 305-325. 